labeled duplex. As might be anticipated, none of the simulated isotropic spectra provide an especially good fit to the dynamic signature of the distinctly anisotropic ${ }^{10}$ long duplex DNA. The spectrum does, however, contain features found in isotropic simulations in the 20-100 ns $\tau_{\mathrm{r}}$ range. ${ }^{11}$ For the present purposes, the signature of a large DNA duplex is easily distinguished from that of the hairpin and single-stranded forms. ${ }^{12}$

The spectra presented here suggest that spin-labeled DNA in combination with EPR is a simple and powerful tool for the structural evaluation of regions of DNA suspected not to exist in the $B$ form. ${ }^{13}$ Large and characteristic differences between duplex and unpaired bases should permit detection of the latter in DNA of any size. Furthermore, the EPR method is not subject to one major problem common to all chemical reactivity probes, that of dynamic equilibration of conformations. In fact, the nanosecond time scale of the EPR method should permit quantitation of such equilibria (e.g., duplex/cruciform equilibria). This spin label method of structure evaluation may also find use as a preliminary characterization of small DNA's whose study by NMR or X-ray diffraction is contemplated. Whether spin probes will reveal distinct signatures for other nucieic acid structures (e.g., A-, Z-, and bent DNA, RNA structures) remains to be found.

Acknowledgment. We thank the National Science Foundation (PCM-82-16762 and DMB-87-06175), National Institutes of Health (GM32681), and the Searle Scholars Program for financial support and E. Hustedt for technical assistance. P.B.H. thanks the National Institutes of Health for a Research Career Development Award (1988-1993) and is a Sloan Fellow (1988-1990).

(10) Barkley, M. D.; Zimm, B. H. J. Chem. Phys. 1979, 70, 2991

(11) Both theoretical and experimental studies are underway to understand the observed spectra.

(12) Bobst has reported minor differences in the single- and doublestranded forms of a less rigidly tethered spin-labeled DNA (see: Bobst, $A$ M.; Kao, S.-C.; Toppin, R. C.; Ireland, J. C.; Thomas, I. E. J. Mol. Biol. 1984 173.63). However, extensive motion of the spin probe independent of the DNA caused the resulting spectra for even long duplex DNA to be dominated by a subnanosecond motion, seriously compromising the sensitivity of such probes to the motional processes characteristic of DNA

(13) To what extent motion of the nitroxide independent of the attached base has affected the EPR signatures recorded here is unknown. The cited $\tau_{\mathrm{r}}$ values should not be assumed to reflect exclusively motion of the pyrimidine heterocycle.

\section{Stereoselective Circumambulatory Methyl Migrations in the Nonamethylcyclopentylium Ion}

\author{
Herbert Mayr* and Rainer Koschinsky \\ Institut für Chemie der Medizinischen Universität zu \\ Lübeck, Ratzeburger Allee 160, D-2400 Lübeck 1 \\ Federal Republic of Germany \\ Received July 11, 1988
}

Degenerate 1,2-rearrangements of carbocations are usually very rapid, and dynamic NMR spectroscopy has been used to determine the barriers of such processes. ${ }^{1}$ Saunders reported a barrier of $3.1 \mathrm{kcal} / \mathrm{mol}$ for the $1,2-\mathrm{H}$ shift in the dimethylcyclopentyl cation $1{ }^{2}$ As the barriers for $1,2-\mathrm{H}$ and $1,2-\mathrm{CH}_{3}$ migrations are of

(1) Reviews: (a) Saunders, M.; Chandrasekhar, J.; Schleyer, P. v. R. In Rearrangements in Ground and Excited States; de Mayo, P., Ed.; Academic Press: New York, 1980; Vol. I, p 1. (b) Siehl, H.-U. Adv. Phys. Org. Chem. 1987, 23,63. (c) Olah, G. A.; Surya Prakash, G. K.: Sommer, J. Superacids Wiley: New York, 1985; p 128. (d) Vogel, P. Carbocation Chemistry; Elsevier: Amsterdam, 1985; pp 142. (e) Telkowski, L. A.; Saunders, M. In Dynamic Nuclear Magnetic Resonance Spectroscopy; Jackman, L. M. Cotton, F. A . Eds : Academic Press: New York, 1975; p 523. (f) Oki, M. Applications of Dynamic NMR Spectroscopy to Organic Chemistry; $\mathrm{VCH}$ Verlagsgesellschaft: Weinheim, 1985; p 378. (g) Brown, H. C. (with comments by Schleyer, P. v. R.) The Nonclassical Ion Problem; Plenum Press: New York, 1977. (h) Shubin, V. G. Top. Curr. Chem. Springer: Berlin, 1984; Vol. $116 / 117$, p 267

(2) Saunders, M.; Telkowski, L.; Kates, M. R. J. Am. Chem. Soc. 1977, 99, 8070

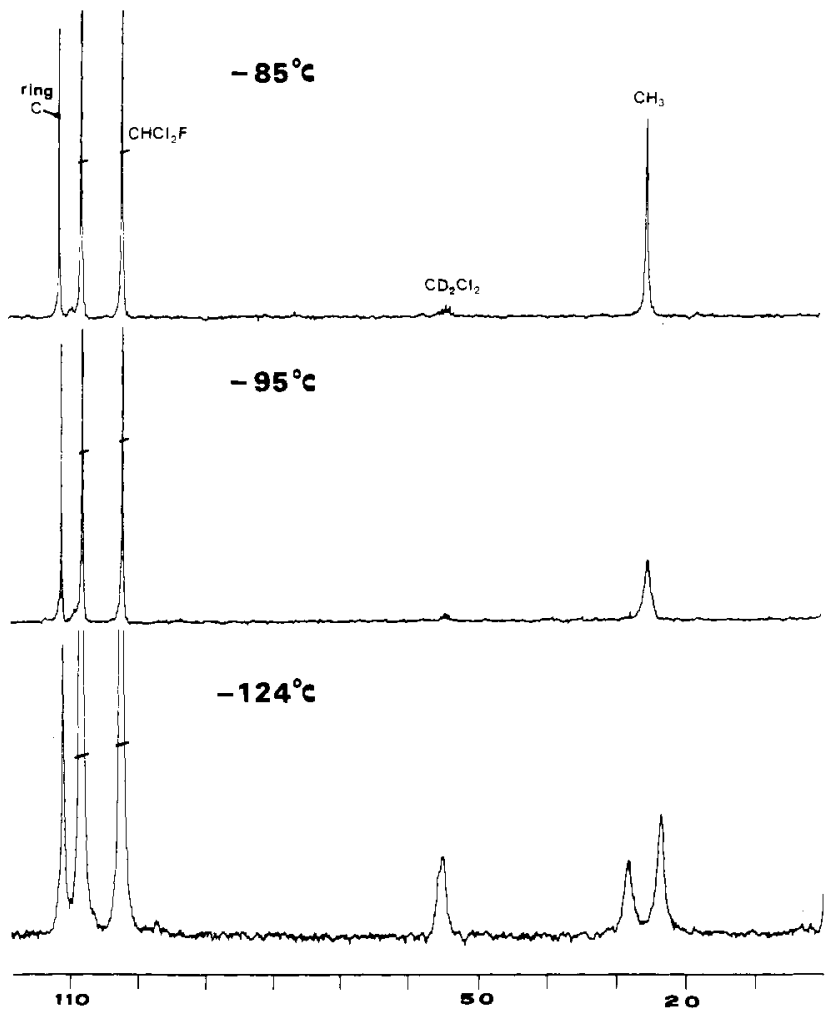

Figure $1 .{ }^{13} \mathrm{C}$ NMR spectra of the nonamethylcyclopentylium ion in $\mathrm{FSO}_{3} \mathrm{H} / \mathrm{SbF}_{5} / \mathrm{SO}_{2} \mathrm{ClF} / \mathrm{CHCl}_{2} \mathrm{~F}$.

similar magnitude in the tetramethyl- and pentamethylethyl cation, ${ }^{3}$ one can estimate the bridged cation $2 \mathrm{a}$ to be $3-4 \mathrm{kcal} / \mathrm{mol}$ less stable than the open cation $\mathbf{2 b}$.

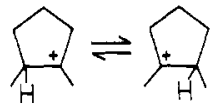

1a
$1 \mathrm{~b}$

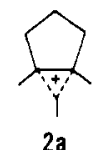

2a

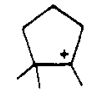

$2 b$
It should be possible to overcompensate this small energy difference by torsional strain, and we had speculated that the nonamethylcyclopentylium ion 3 might possess a methyl-bridged structure, since the classical structure $3 \mathbf{a}$ incorporates four adjacent quaternary carbon centers.

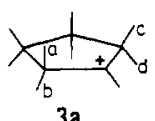

$3 a$

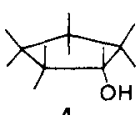

When nonamethylcyclopentanol $4,{ }^{4 a}$ prepared from octamethylcyclopentanone ${ }^{4 b, c}$ and $\mathrm{CH}_{3} \mathrm{Li}$, was dissolved in a solution of $\mathrm{FSO}_{3} \mathrm{H} / \mathrm{SbF}_{5}$ in $\mathrm{SO}_{2} \mathrm{ClF}^{5}$ at $-90{ }^{\circ} \mathrm{C}$, a single peak $(\delta 1.86)$ was observed in the $200 \mathrm{MHz}{ }^{1} \mathrm{H}$ NMR spectrum, indicating total scrambling of all methyl groups, analogous to the spectra previously reported for the unsubstituted cyclopentylium ion. ${ }^{6}$ Decomposition of 3 with formation of tert-butyl cations takes place at $T>-70^{\circ} \mathrm{C}$. When the solution of 3 in $\mathrm{SO}_{2} \mathrm{ClF} / \mathrm{CHCl}_{2} \mathrm{~F}$ was cooled, the ${ }^{l} \mathrm{H}$ NMR signal broadened, and, at $-137^{\circ} \mathrm{C}$, two resonances at $\delta 2.00$ and 1.63 with relative intensities 5:4 were observed.

(3) Saunders, M.; Kates, M. R. J. Am. Chem. Soc. 1978, 100, 7082 (4) (a) Wehle, D.; Scheuermann, H.-J.; Fitjer, L. Chem. Ber. 1986, 119 3127. (b) Fitjer, L.; Wehle, D.; Scheuermann, H.-J. Chem. Ber. 1986, 119, 1162. (c) Mayr, H.; Koschinsky, R.; Will, E.; Bäuml, E. J. Org. Chem. 1987, 52,1342

(5) Reference $1 \mathrm{c}, \mathrm{p} 42$

(6) (a) Olah, G. A.; Lukas, J. J. Am. Chem. Soc. 1968, 90, 933. (b) Olah, G. A.; White, A. M. J. Am. Chem. Soc. $1969,91,3954$ (c) Myhre, P. C. Kruger, J. D.; Hammond, B. L.; Lok, S. M; Yannoni, C. S.; Macho, V.; Limbach, H. H.; Vieth, H. M. J. Am. Chem. Soc. 1984, 106, 6079. 
Line shape analysis ${ }^{7}$ of the $200 \mathrm{MHz}{ }^{1} \mathrm{H}$ NMR spectra taken between -103 and $-137^{\circ} \mathrm{C}$ yields $\Delta \nu=82 \mathrm{~Hz}$ and $k_{\mathrm{A}}=246 \mathrm{~s}^{-1}$ and $k_{\mathrm{B}}=308 \mathrm{~s}^{-1}\left(-120^{\circ} \mathrm{C}\right)$ for the exchange between $\mathrm{A}$ and $\mathrm{B}$ with a population ratio $P_{\mathrm{A}}: P_{\mathrm{B}}=5: 4$. A barrier of $\Delta G^{*}\left(-120^{\circ} \mathrm{C}\right)$ $=7.0 \mathrm{kcal} / \mathrm{mol}$ is thus obtained for the process which equalizes all methyl groups.

In accord with the ${ }^{1} \mathrm{H}$ NMR spectra, the $50 \mathrm{MHz}{ }^{13} \mathrm{C}$ NMR spectrum taken at $-80^{\circ} \mathrm{C}$ showed only two resonances at $\delta 110.88$ (ring $\mathrm{C}$ ) and $\delta 25.42\left(\mathrm{CH}_{3}\right)$. When the solution was cooled at $-124^{\circ} \mathrm{C}$, the methyl signal was split into two resonances at $\delta 28.17$ and 23.57 (ratio $4: 5$ ), ${ }^{8}$ while the $\delta 110.88$ signal remained sharp (Figure 1). The signal of the ring carbons does not show line broadening even at $-135^{\circ} \mathrm{C}$, indicating a barrier of less than 2.5 $\mathrm{kcal} / \mathrm{mol}$ for the circumambulatory process.

These spectra indicate that rapid circumambulatory methyl migrations take place, while a set of four methyl groups remains separate from a second set of five methyls. This observation excludes the $C_{2 v}$ ground-state geometry $3 \mathbf{a}$ of the title cation, since in this case the migrations of the methyl groups $a, b, c$, and $d$ had equal probability, and all methyl groups should become equivalent during the circumambulatory process.

The methyl-bridged cation $3 \mathbf{b}$, however, might account for the observed 4:5 methyl splitting, since the 1,2-methyl migrations can be expected to proceed with inversion at the ring carbons. ${ }^{9}$ As shown in eq 1 , only the dotted methyl groups will circumambulate, while the starred methyls move up and down at fixed ring positions. Scrambling between the two sets of methyl groups does not take place.

A similar behavior can be expected for the partially bridged structures $3 \mathrm{c}$, and the rate of the equilibration $3 \mathrm{c} \rightleftarrows 3 \mathrm{c}^{\prime}$ can be assumed to be higher or lower than the rate of the methyl migrations.
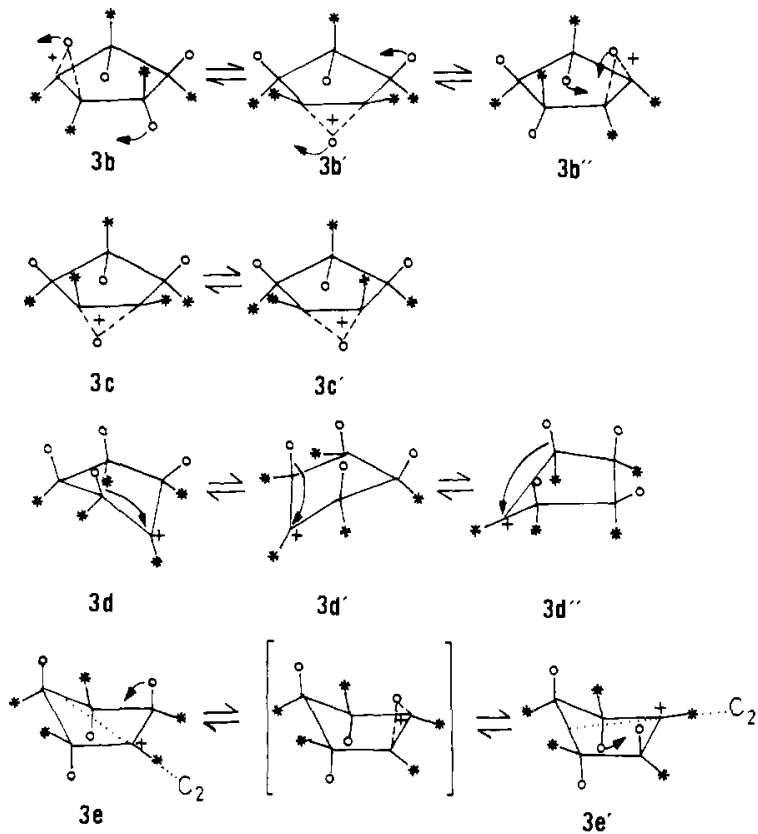

It is possible, however, to explain the nonequivalence of the two sets of methyl groups also with the assumption of classical carbenium ions with a nonplanar five-membered ring. If the ground state were a nonbridged cation with $C_{s}$ symmetry (3d), the dotted methyl groups, which are adjacent to the carbenium center, can be expected to migrate preferentially, since they possess the proper orientation for interaction with the vacant $p$ orbital. 1,2-Migration

(7) Günther, H. NMR-Spektroskopie; 2. Aufl., Thieme: Stuttgart, 1983; p 225

(8) The pulse sequence of $1.3 \mathrm{~s}\left(35^{\circ}\right.$ pulses) warranted complete longitudinal relaxation, and the $4: 5$ averaged signal coincides with the chemical shift observed in the completely degenerate cation.

(9) (a) March, J. Advanced Organic Chemistry, 3rd ed.; Wiley: New York, 1985; p 942. (b) Deslongchamps, P. Stereoelectronic Effects in Organic Chemistry; Pergamon Press: Oxford, 1983; p 190. might generate a second nonplanar ring $\left(\mathbf{3 d}^{\prime}\right)$, and the four migrating methyl groups above the ring may remain separate from the nonmigrating five methyls below the ring.

In a classical carbenium ion with $C_{2}$ symmetry ( $\left.3 \mathbf{e}\right)$, the methyl groups in axial position (dotted) are colinear with the empty $p$ orbital and have a greater migrating ability than the equatorial methyl groups. This structure may account for the observed $4: 5$ splitting, if the axial and equatorial methyl groups retain their individual steric positions during the methyl shifts, as indicated by eq 4 .

If one eliminates the classical structure $\mathbf{3 d}$, which was found to be $4.5 \mathrm{kcal} / \mathrm{mol}$ less stable than $3 \mathrm{e}$ on the basis of force field calculations, ${ }^{10}$ one has to consider structures $3 \mathbf{b}, \mathbf{c}$ and e as potential ground-state geometries.

The total ${ }^{13} \mathrm{C}$ chemical shift difference between carbocations and the corresponding saturated hydrocarbons has been used as a probe for bridging. ${ }^{11}$ Whereas $\Delta \delta$ values of 350 ppm or more were found for classical cations, smaller shift differences were usually observed for bridged cations. For cation 3, the sum of chemical shifts is calculated to be approximately $340-350 \mathrm{ppm}$ greater than in the corresponding saturated hydrocarbon, ${ }^{4 a}$ thus favoring a classical, perhaps a weakly bridged structure ( $3 \mathrm{e}$ or 3c).

In trivalent carbenium ions, carbon atoms directly attached to the carbenium center are usually strongly deshielded, while carbons in $\beta$ position experience a slight upfield shift (see compounds 5 and 6 ). ${ }^{12}$
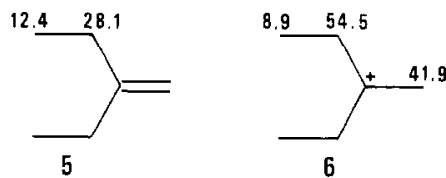

In the carbenium ions $3 \mathrm{~d}$ or $3 \mathrm{e}$, the set of starred methyl groups which includes the methyl group directly attached to the carbenium center, is therefore expected to absorb at lower field, if the shift difference of the nonequivalent $\beta$-methyl groups is assumed to be small. Since the five-methyl ${ }^{13} \mathrm{C}$ NMR signal of 3 absorbs at higher field than the four-methyl signal, classical ground-state structures are disfavored.

On the basis of chemical shift considerations, the partially bridged structure $3 \mathrm{c}$ thus appears to be most probable, but the alternatives $\mathbf{3 b}$ and $\mathbf{3 e}$ cannot be excluded. It should be mentioned that in analogy to our finding 1,2-hydride shifts have recently been reported to be faster in the all-trans-1,2,3,4,5-pentamethylcyclopentyl cation than in the all-cis isomer. ${ }^{13}$ Since the circumambulatory process cannot be frozen out at $-135^{\circ} \mathrm{C}$, isotope labeling ${ }^{16}$ and $/$ or solid-state NMR experiments ${ }^{14}$ will be needed to obtain unequivocal evidence for the structure of 3 .

Acknowledgment. We thank Prof. P. v. R. Schleyer for stimulating this work and for bringing the topology of the trans migrations to our attention, Prof. H. Günther and Dipl. Chem. W. Leber for carrying out the line shape analyses, and the Deutsche Forschungsgemeinschaft and the Fonds der Chemischen Industrie for financial support.

Registry No. 3, 119009-90-4; 4, 103457-83-6.

Supplementary Material Available: Experimental and simulated $200 \mathrm{MHz}{ }^{1} \mathrm{H}$ NMR spectra (6 pages) of 3 . Ordering information is given on any current masthead page.

(10) MMPM 1: (a) Allinger, N. L. J. Am. Chem. Soc. 1977, 99, 8127. (b) Gajewski, J. J.; Gilbert, K. E. Molecular Mechanics Package (MS-DOS Computers); Serena Software: Bloomington, IN

(11) Schleyer, P. v. R.; Lenoir, D.; Mison, P.; Liang, G.; Surya Prakash G. K. Olah, G. A. J Am Chem Soc 1980, 102, 683

(12) Olah, G. A.; Donovan, D. J. J. Am. Chem. Soc. 1977, 99, 5026.

(13) Sorensen, T. S.; Whitworth, S. M. Paper No. 428, Organic Division, ACS Abstracts; Third North American Chemical Congress: Toronto, Canada June 1988.

(14) (a) Yannoni, C. S.; Myhre, P. C.; Macho, V. J. Am. Chem. Soc. 1982 104, 7380. (b) Yannoni, C. S.; Myhre, P. C.; McLaren, K. L. J. Am. Chem. Soc. 1985, 107, 5294 . 